\title{
Parallel kinetic resolution of intramolecular furan Diels-Alder cycloadducts via asymmetric hydroboration
}

\author{
Tamara Fulgheri, ${ }^{[a]}$ Philip Cornwall, ${ }^{[b]}$ Andrew R. Turne \\ Abstract: We report parallel kinetic resolution of intramolecular
Diels-Alder cycloadducts, where up to five stereocentres are defined \\ using asymmetric hydroboration as the enantiodiscriminating \\ reaction, and reveal evidence for dynamic kinetic resolution based \\ on a reversible cycloaddition.
}

\section{Introduction}

Synthetic methods to access chiral molecules containing multiple defined stereocentres are in growing demand. The presence of asymmetric centres within molecular frameworks is widely acknowledged as a desirable attribute ${ }^{[1]}$ especially in biological contexts. ${ }^{[2,3]}$ Simple kinetic resolution (KR, Figure $\left.1 \mathrm{~A}\right)$, where the substrate enantiomers react at different rates with a enantiotopically discriminating reagent or catalyst, is an effective but inherently inefficient enantioenrichment strategy to access such materials in enantioenriched form. As the more reactive enantiomer is depleted, the relative reaction rates converge, necessitating exceptional selectivity factors ${ }^{[4]}$ to deliver the product in acceptable yield with high levels of enantiomeric purity. ${ }^{[5]}$ Where the substrate enantiomers undergo fast interconversion, dynamic kinetic resolution (DKR, Figure $1 \mathrm{~B})$ is possible: ${ }^{[6]}$ a deracemisation process ${ }^{[7]}$ in which both antipodes of substrate are eventually converted into product. As both enantiomers are consumed at comparable rates, useful transformations can be realised using reactions with modest selectivity factors. ${ }^{[8]}$

A chiral catalyst or reagent(s) can also react with the enantiomers of a racemic substrate to give non-enantiomeric products: a divergent reaction on a racemic mixture (DRRM).$^{[9]}$ The term parallel kinetic resolution (PKR, Figure 1C), ${ }^{[10]}$ introduced by Vedejs and Chen to describe the reaction of two chiral acylating reagents, each reacting at a faster rate with antipodal alcohols, has been subsequently employed by others

[a] Dr. D. M. Gill, ${ }^{*}$ Dr. T. Fulgher

Department of Chemical Sciences

University of Huddersfield

Queensgate, Huddersfield HD1 3DH UK

Email: d.m.gill@hud.ac.uk

https://pure.hud.ac.uk/en/persons/duncan-gill

[b] A. R. Turner, Dr. P. Cornwall

Early Chemical Development, Pharmaceutical Sciences

R\&D, AstraZeneca

Macclesfield, UK

[c] Prof. J. B. Sweeney

Department of Chemistry

University of Lancaster

Lancaster LA1 4YB UK

Supporting information for this article is given via a link at the end of the thoumant to describe DRRM reactions involving a single reagent or catalyst. ${ }^{[1]}$ This relatively uncommon class of reaction has considerable potential compared to standard $K R$, and is complementary to DKR in utility. As in the case of DKR, if both substrate enantiomers react at similar rates, high selectivity factors are not required to achieve acceptable levels of asymmetric induction. Whereas DKR of compounds containing multiple stereocentres requires a mechanism to racemise the substrate without the production of other stereoisomers, PKR processes are not constrained by this limitation.

A. Enantiomers have different rate of reaction: kinetic resolution (KR)

\begin{tabular}{|c|c|c|}
\hline A & Fast $\mathbf{B}$ & Product $\mathrm{B} \leq 50 \%$ yield and e.r. \\
\hline$A^{\prime}$ & Slow $\rightarrow B^{\prime}$ & \\
\hline & $(\mathrm{O}) \mathrm{R}^{3} \stackrel{\text { lipase }}{ }$ & $Y_{\mathrm{R}^{2}}^{\mathrm{OH}}+\mathrm{R}_{\mathrm{R}^{2}}^{1}{ }^{\prime \prime} \mathrm{O}-\mathrm{C}(\mathrm{O}) \mathrm{R}^{3}$ \\
\hline
\end{tabular}

B. Slow-reacting enantiomer can epimerise: dynamic kinetic resolution $(\mathrm{DKR})^{[6 \mathrm{c}]}$

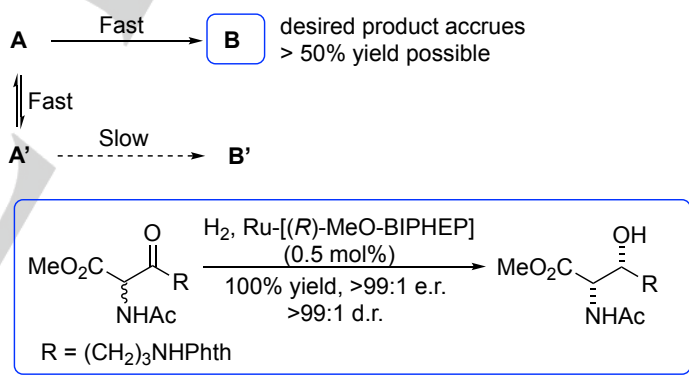

C. Enantiomers give different products: parallel kinetic resolution $(\mathrm{PKR})^{[11 \mathrm{~b}]}$
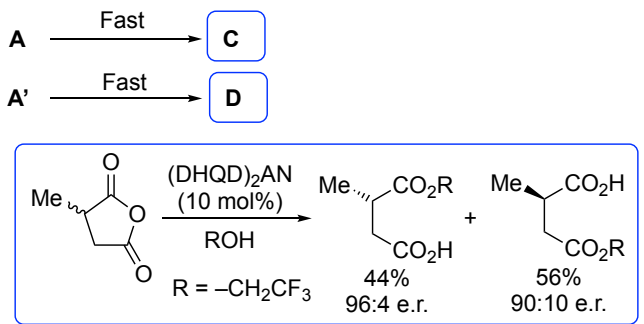

Figure 1. Kinetic resolution strategies.

Although cycloaddition reactions are historically significant processes in synthetic organic chemistry, kinetic resolution protocols have rarely been applied to cycloaddition products, with prior reports being largely confined to simple $\mathrm{KR}$ chemistry. ${ }^{[12]}$ First reported by Cram in $1961,{ }^{[13]}$ intramolecular 
Diels-Alder furan (IMDAF) cycloadditions ${ }^{[14]}$ are widely used in the synthesis of natural products, ${ }^{[15]}$ drugs, ${ }^{[16]}$ and lead-like $\mathrm{sp}^{3}$ heterocyclic scaffolds (Figure 2). ${ }^{[17]}$ In many instances, the position of equilibrium in IMDAF reactions is governed by reversible kinetics, and is readily perturbed by subtle changes in reaction conditions and substrate structure. ${ }^{[18]}$ This has limited the synthetic application of such transformations, particularly the development of enantioselective variants. Only modest success has been achieved using chiral auxiliaries, ${ }^{[19]}$ and catalytic asymmetric IMDAF cycloaddition reactions have not been reported. On the other hand, application of a DKR- or PKRbased transformation to IMDAF cycloadditions has the potential to overcome reversibility, and create multiple stereocentres with relative and absolute control. We report here the first regiodivergent reactions of racemic IMDAF cycloadducts, using hydroboration as a processing reaction, and reveal evidence for simple, parallel and dynamic kinetic resolution processes within the same reaction manifold.
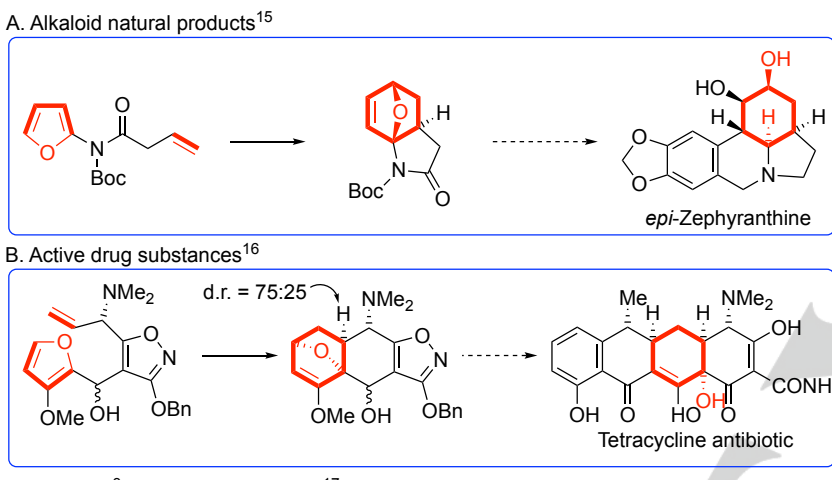

C. Novel $\mathrm{sp}^{3}$ heterocyclic scaffolds ${ }^{17}$

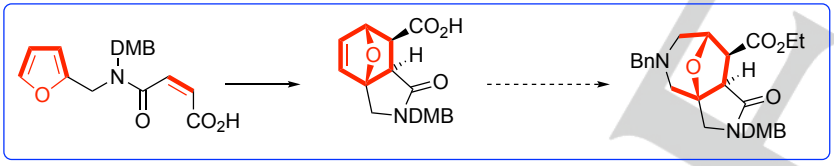

D. Reversibility compromises efficiency

$$
\text { Me }
$$

Figure 2. Intramolecular Diels-Alder furan cycloaddition reactions: useful but reversible synthetic processes.

Selective olefin exo-functionalisation ${ }^{[20]}$ of racemic IMDAF cycloadduct ( \pm )-A with a chiral borane will give up to four isomeric products: reaction of $\mathbf{A}$ will give regioisomers $\mathbf{B}$ and $\mathbf{C}$, whereas enantiomer A' will give B' and 'C' (Scheme 1). Depending on the relative reaction rates leading to each product, $K R, D K R$ or regiodivergent PKR may be observed. If substrate racemisation (interconversion of $\mathbf{A}$ and $\mathbf{A}^{\prime}$ ) is slow, simple $\mathrm{KR}$ will convert $\mathbf{A}$ to $\mathbf{B}$ and/or $\mathbf{C}$, with recovery of the less reactive substrate enantiomer $\mathbf{A}^{\prime} \quad$ (Scheme $\left.1 \mathrm{~A}\right)$. If interconversion of $\mathbf{A}$ and $\mathbf{A}^{\mathbf{\prime}}$ is much faster than reaction of $\mathbf{A}^{\prime}$ to give $\mathbf{B}^{\prime} / \mathbf{C}^{\prime}$, then both $\mathbf{A}$ and $\mathbf{A}^{\prime}$ ' will be consumed to give $\mathbf{B}$ and/or C via DKR (Scheme 1B). If racemisation is slow, and both enantiomers react at similar rates to give regioisomeric products, PKR will be observed; thus, $\mathbf{B}$ and $\mathbf{C}^{\prime}$ are produced from $\mathbf{A}$ and

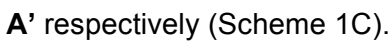

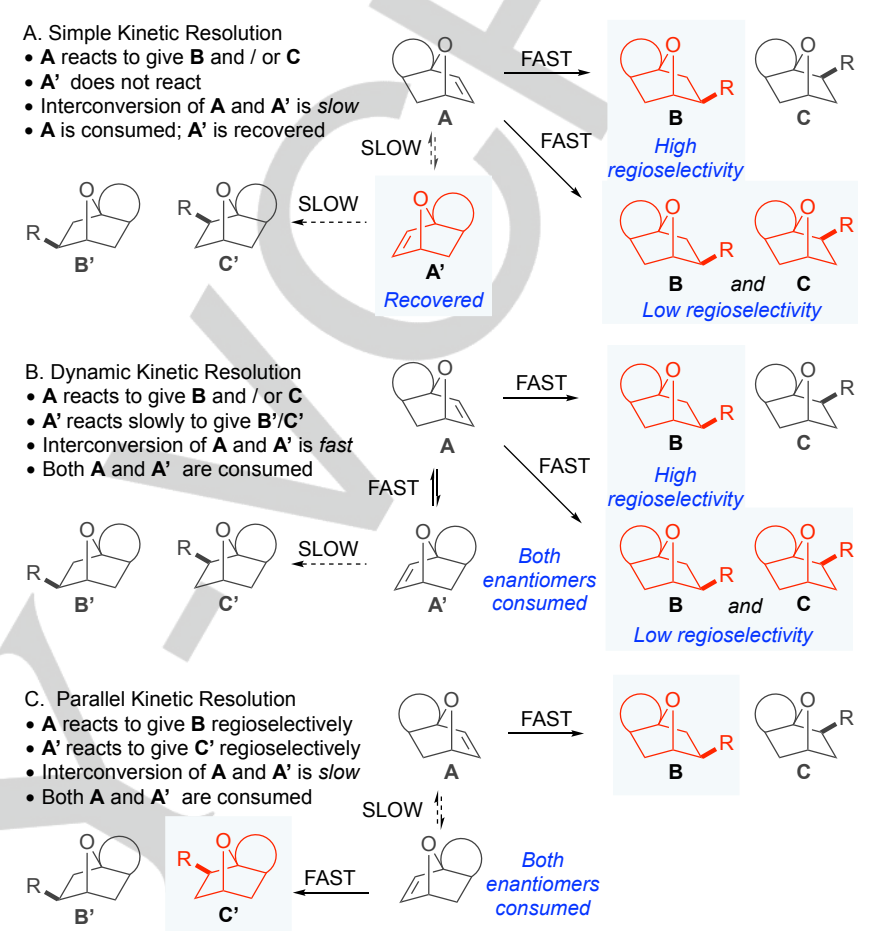

Scheme 1. IMDAF cycloadduct kinetic resolution processes.

\section{Results and Discussion}

Cycloaddition of furanoacrylamide $\mathbf{3 a}$ proceeded spontaneously during its synthesis: the only detectable product of the reaction of amino $1 \mathbf{a}$ with acid $2 \mathbf{a}$ in the presence of peptide coupling reagents is cycloadduct $(\mathbf{(}) \mathbf{- 4 a}$. Treatment of $(\mathbf{(}) \mathbf{- 4 a}$ with diisocampheyl borane, $(-)-(\mathrm{lpc})_{2} \mathrm{BH}^{[21]}$ in THF at $0^{\circ} \mathrm{C}$ over $8 \mathrm{hrs}$ occurred with complete exo-selectivity. After oxidation with sodium borate, ${ }^{[22]}$ a 50:50 mixture of structural isomers 5 a and 6a was obtained (Table 1, entry 1 ). The isomers were separated and analysed by standard methods, ${ }^{[23]}$ enabling determination of enantiomer ratios and absolute configurations of the products (see Supporting Information). In line with Houk's model ${ }^{[24]}$ for hydroboration of prochiral olefins using this reagent, each cycloadduct enantiomer had reacted preferentially to give $S$ configured alcohols. Lowering the temperature to $-40^{\circ} \mathrm{C}$ led to a modest selectivity for isomer $\mathbf{6 a}$, which was obtained with a similar e.r. (76:24); gratifyingly, minor regioisomer $\mathbf{5 a}$ was obtained with an e.r. of 94:6 (entry 2). Further reduction in

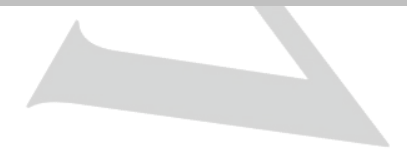


reaction temperature to $-78{ }^{\circ} \mathrm{C}$ completely inhibited the reaction (entry 3). Variation in solvent composition (to an $\mathrm{Et}_{2} \mathrm{O} / \mathrm{THF}$ mixture $)^{[25]}$ led to complete reaction within $8 \mathrm{hr}$ at $-20^{\circ} \mathrm{C}$, and delivered both regioisomers with high enantiomeric purity (5a e.r. $=97: 3$; 6 a e.r. $=95: 5$; entry 4). Thus, the cycloadduct enantiomers reacted at similar rates to give non-enantiomeric products, confirming that PKR had taken place.

We examined a range of cycloadducts $(\mathbf{4 b}-\mathbf{4 h})$ in the process (entries 5-12). It became clear that reactivity in the hydroboration reaction was related to steric encumbrance around the tether carbonyl: for less hindered substrates such as $4 b$ and $4 e\left(R^{2}=\right.$ $\mathrm{H}$; entries 5 and 9), competitive complexation of the reagent to the tether carbonyl retarded the rate. Hydroboration of these substrates did not occur at $-20{ }^{\circ} \mathrm{C}$, only proceeding at an appreciable rate at room temperature. Under these conditions, formation of the 5 -substituted products ( $6 \mathbf{b}$ and $\mathbf{6 e}$ ) was slightly favoured, but stereoselectivity was eroded, and overall yields were lower, possibly reflecting competing lactam reduction at the higher reaction temperature. ${ }^{[26]}$ Methyl-substituted analogue 4c (entry 7) proved to be intermediate in reactivity and stereoselectivity (compared to $\mathbf{4 a}$ and $\mathbf{4 b}$; entries 2 and 5 ); likewise, $4 d\left(R^{2}=B r\right.$; entry 8$)$ reacted relatively slowly, but gave excellent selectivity for both $S$-configured regioisomers, which were both obtained with e.r. $=98: 2$.

In comparison with $\mathbf{4 a}$ and $\mathbf{4 c}, 6$-substituted cycloadduct analogues $\mathbf{4 f}-\mathbf{h}$ reacted more slowly. No reaction was observed between 6-bromo-substituted cycloadduct $\mathbf{4} \mathbf{f}$ and either $\mathrm{BH}_{3}$ or $\mathrm{Ipc}_{2} \mathrm{BH}$ (presumably due to the deactivating effect of the electron-withdrawing halogen substituent). After $8 \mathrm{hr}$ at $-20^{\circ} \mathrm{C}$, reaction of $4 \mathrm{~h}$ with $\mathrm{Ipc}_{2} \mathrm{BH}$ had proceeded to $66 \%$ conversion. After oxidation of the crude boranes, analysis of the product composition showed that the process was selective for the $4-\mathrm{OH}$

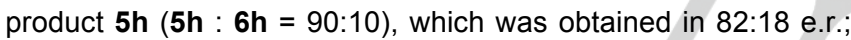
the more hindered $5-\mathrm{OH}$ isomer $\mathbf{6 h}$ was isolated in 98:2 ratio. In both cases the major stereoisomer was the S-configured alcohol. The remaining cycloadduct $4 \mathrm{~h}$ was recovered as a single enantiomer, indicating that effective kinetic resolution had taken place. Dimethyl cycloadduct $\mathbf{4 g}\left(\mathrm{R}^{1}, \mathrm{R}^{2}=\mathrm{Me}\right.$; entry 12) was also not completely converted to products at $-20^{\circ} \mathrm{C}$, though minor product $\mathbf{6 g}$ was obtained in the highest stereoselectivity yet observed (e.r. $=>99: 1$ ). These outcomes can be rationalized using the Houk model: the lowest energy transition states leading to the $4-S$ and $5-S$ isomers experience minimal steric interactions between the borane ligands and oxanorbornene oxygen. ${ }^{[24]}$ An additional interaction between 6-Me group and ligand disfavours formation of the $5-S$ isomer, outweighing a similar effect exerted by the tether methylene group. The transition states leading to the 4-R and 5-R isomers both suffer from unfavourable interactions between ligand and oxanorbornene oxygen; in the latter case, an additional clash with the 6-Me group accounts for the very low proportion of this isomer formed.

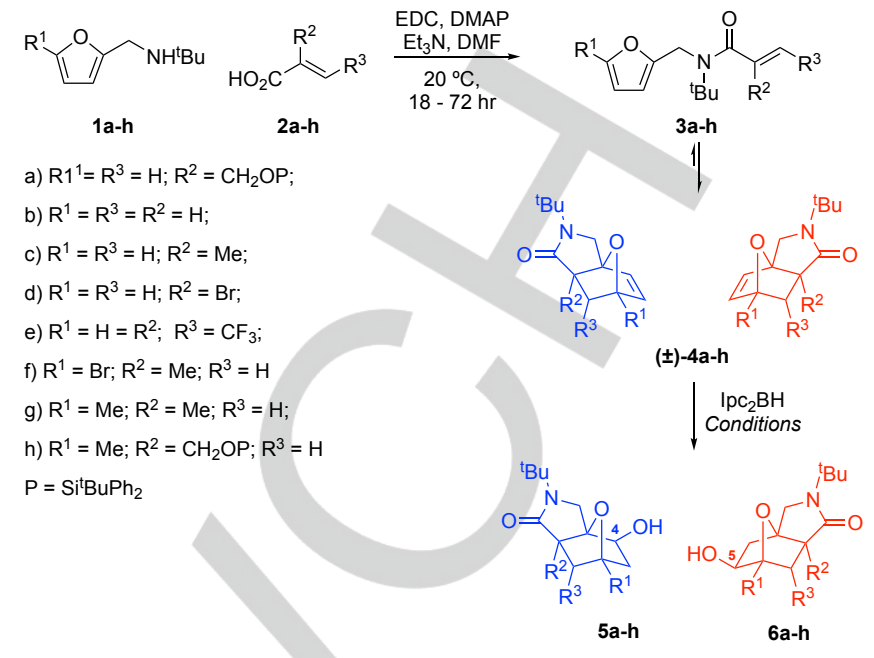

Table 1. PKR via asymmetric hydroboration.

\begin{tabular}{|c|c|c|c|c|c|}
\hline Entry & Substrate & Conditions $^{[\mathrm{a}]}$ & & Yield (e. & \\
\hline 1 & & & 4 & 5 & 6 \\
\hline 1 & $4 a$ & A & $0(-)$ & $\begin{array}{c}5 a 32 \\
(75: 25)\end{array}$ & $\begin{array}{c}6 a 32 \\
(76: 24)\end{array}$ \\
\hline 2 & $4 a$ & B & $0(-)$ & $\begin{array}{l}5 a 30 \\
(94: 6)\end{array}$ & $\begin{array}{c}6 a 37 \\
(76: 24)\end{array}$ \\
\hline 3 & $4 a$ & C & 4a 100 & - & - \\
\hline $4^{[b]}$ & $4 a$ & D & $0(-)$ & $\begin{array}{l}5 a 38 \\
(97: 3)\end{array}$ & $\begin{array}{l}6 \text { a } 38 \\
(95: 5)\end{array}$ \\
\hline $5^{[\mathrm{c}]}$ & $4 b$ & $E$ & $0(-)$ & $\begin{array}{l}\mathbf{5 b} 30 \\
(92: 8)\end{array}$ & $\begin{array}{c}6 \mathbf{6 b} 37 \\
(80: 20)\end{array}$ \\
\hline 6 & $4 b$ & D & 4b 100 & - & - \\
\hline $7^{[\mathrm{c}]}$ & 4c & D & $\begin{array}{c}4 c 5 \\
(81: 19)\end{array}$ & $\begin{array}{l}5 c 30 \\
(96: 4)\end{array}$ & $\begin{array}{c}6 c 37 \\
(90: 10)\end{array}$ \\
\hline 8 & 4d & D & $\begin{array}{c}4 d 36 \\
(50: 50)\end{array}$ & $\begin{array}{l}5 d 21 \\
(98: 2)\end{array}$ & $\begin{array}{l}\text { 6d 22 } \\
(98: 2)\end{array}$ \\
\hline 9 & $4 e$ & $E$ & $0(-)$ & $\begin{array}{c}\text { 5e } 17 \\
(79: 21)\end{array}$ & $\begin{array}{c}6 e-45 \\
(63: 37)\end{array}$ \\
\hline 10 & $4 e$ & $\mathrm{~F}$ & $\begin{array}{c}4 \text { e } 41 \\
(59: 41)\end{array}$ & $\begin{array}{c}\mathbf{5 f} 21 \\
(89: 11)\end{array}$ & $\begin{array}{c}6 f 38 \\
(87: 13)\end{array}$ \\
\hline 11 & $4 f$ & G & 4f 100 & - & - \\
\hline 12 & $4 g$ & D & $\begin{array}{l}\mathbf{4 g ~} 26 \\
(98: 2)\end{array}$ & $\begin{array}{c}\mathbf{5 g} 48 \\
(82: 18)\end{array}$ & $\begin{array}{c}6 \mathbf{g ~ 3} \\
(>99: 1)\end{array}$ \\
\hline 12 & $4 \mathrm{~h}$ & D & $\begin{array}{c}\text { 4h } 34 \\
(>99: 1)\end{array}$ & $\begin{array}{c}5 \text { h } 61 \\
(82: 18)\end{array}$ & $\begin{array}{c}\text { 6h 5 } \\
(98: 2)\end{array}$ \\
\hline
\end{tabular}

[a] A: $0{ }^{\circ} \mathrm{C}, 8 \mathrm{~h}, \mathrm{THF} ; \mathrm{B}:-40{ }^{\circ} \mathrm{C}, 8 \mathrm{hr}, \mathrm{THF} ; \mathrm{C}:-78{ }^{\circ} \mathrm{C}, 8 \mathrm{hr}, \mathrm{THF}$; D: $-20{ }^{\circ} \mathrm{C}, 8 \mathrm{hr}$, $\mathrm{Et}_{2} \mathrm{O} / \mathrm{THF}$ (85/15); $\mathrm{E}: 20{ }^{\circ} \mathrm{C}, 18 \mathrm{hr}, \mathrm{Et}_{2} \mathrm{O} / \mathrm{THF}$ (85/15); $\mathrm{F}:-0{ }^{\circ} \mathrm{C}, 4$ days, $\mathrm{Et}_{2} \mathrm{O} / \mathrm{THF}$ (85/15); G: $20{ }^{\circ} \mathrm{C}, 24 \mathrm{hr}$. 
[b] Isolated as 4-bromobenzoate esters.

[c] Inseparable mixture of $\mathbf{5}$ and $\mathbf{6}$ obtained. Yields for $\mathbf{5}$ and $\mathbf{6}$ determined by ${ }^{1} \mathrm{H}$ NMR analysis.

Evidence for dynamic kinetic resolution could be inferred by comparison of the molar proportions (mol\%) of each enantiomer of products 5 and $\mathbf{6}$ and unreacted substrate $\mathbf{4}$ present in the crude product isolated from each reaction. The major $S$ configured alcohol 5 and minor $R$-configured alcohol 6 both derive from the same enantiomer of $4 ;(R)-5$ and $(S)-6$ are produced from its antipode. In the absence of dynamic equilibration of substrate enantiomers, the mol\% ratio of products and recovered $\mathbf{4}$ derived from each enantiomer of $\mathbf{4}$ will be $50: 50$, and in the case of substrates $4 a-e$, this was found to be the case. Moreover, where unreacted substrate 4 was recovered, little if any enantioenrichment was observed. This suggests that both enantiomers reacted at similar rates, typical of a PKR. However, as shown in Scheme 2, for $\mathbf{4 g}$ the ratio of products and recovered $\mathbf{4 g}$ derived from the respective substrate enantiomers is 57.3:42.7, indicating that deracemisation had taken place. In this reaction, the substrate enantiomers reacted at different rates, evidenced by the presence of enantioenriched $\mathbf{4} \mathbf{g}$ in the crude product. It would appear that racemisation of the slower-reacting $7 \mathrm{a}(S) \mathbf{- 4 g}$ (by retrocyclisation - cycloaddition) is sufficiently fast to promote background DKR.

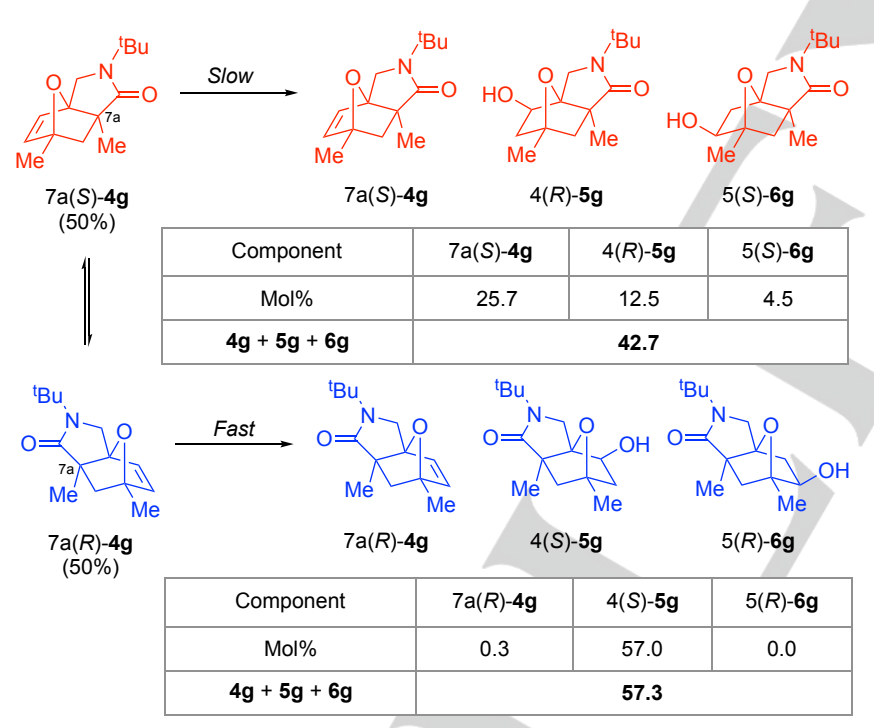

Scheme 2. Evidence for dynamic kinetic resolution in asymmetric hydroboration of $\mathbf{4 g}$.

\section{Conclusions}

In summary, racemic $6-\mathrm{H}$ IMDAF cycloadducts $\mathbf{4 a}-\mathbf{4 d}$ undergo asymmetric exo-selective hydroboration with $(-)-(\mathrm{Ipc})_{2} \mathrm{BH}$, giving mixtures of alcohols 5a-d and 6a-d in high enantiomer ratios upon oxidative workup. The substrate enantiomers react at similar rates to deliver regioisomeric products via parallel kinetic resolution. The enantiomers of $6-\mathrm{Me}$ compounds $\mathbf{4 g}$ and $\mathbf{4 h}$ reacted at different rates, resulting in kinetic resolution; enantioenriched unreacted substrate was recovered, along with unequal amounts of products $\mathbf{5 g}-\mathbf{h}$ and $\mathbf{6 g}-\mathbf{h}$. Analysis of the enantiomer ratios for the reaction of $\mathbf{4 g}$ indicated that deracemisation had occurred. This points the way to the development of processes where cycloadduct racemisation (perhaps accelerated by catalysis) is much faster than functionalisation of the slower-reacting cycloadduct enantiomer, resulting in efficient DKR to favour the formation of a single regio- and stereoisomer. Further studies towards this goal are ongoing and will be reported in due course.

\section{Acknowledgements}

We are grateful to the University of Huddersfield and AstraZeneca (T. F.) for funding.

Keywords: cycloaddition • enantioselectivity • hydroboration • kinetic resolution $\cdot$ regioselectivity

[1] F. Lovering, J. Bikker, C. Humblet, J. Med. Chem. 2009, 52, 6752.

[2] S. Caille, S. Cui, M. M. Faul, S. M. Mennen, J. S. Tedrow, S. D. Walker, J. Org. Chem. 2019, 84, 4583.

[3] a) P. Jeschke, Pest Manag. Sci. 2018, 74, 2389; b) M. Zhang, G. Qing, T. Sun, Chem. Soc. Rev. 2012, 41, 1972.

[4] Defined as the ratio of rate constants for the reaction of each enantiomer substrate. See: H. B. Kagan, Top. Stereochem. 1988, 18, 249.

[5] L. Meurling, G. Bergson, U. Obenius, Chem. Scripta 1976, 9, 9.

[6] a) V. Bhat, E. R. Whelin, X. Guo, B. M. Stolz, Chem. Rev. 2017, 117 4528; b) R. S. Ward, Tetrahedron Asymm. 1995, 6, 1475; c) E. Coulon, M. C. Caño de Andrade, V. Ratovelomanana-Vidal, J.-P. Genêt, Tetrahedron Lett. 1998, 39, 6467

[7] A. R. A. Palmans, Mol. Sys. Des. Eng. 2017, 2, 34.

[8] M. Breuer, K. Ditrich, T. Habicher, B. Hauer, M. Keßeler, R. Stürmer, K. Zelinski, Angew. Chem. Int. Ed. Engl. 2004, 43, 788.

[9] H. B. Kagan, Tetrahedron 2001, 57, 2449.

[10] a) E. Vedejs, X. Chen, J. Am. Chem. Soc. 1997, 119, 2584; b) E. Vedejs, M. Jure, Angew. Chem. Int. Ed. Engl. 2005, 44, 3974.

[11] a) J. R. Dehli, V. Gotor, Chem. Soc. Rev. 2002, 31, 365; b) Y. Chen, L. Deng, J. Am. Chem. Soc. 2001,123, 11302; c) A. S. Kamlet, C. Préville K. A. Farley, D. W. Piotrowski, Angew. Chem. Int. Ed. 2013, 52, 10607; d) L. C. Miller, J. M. Ndungu, R. Sarpong, Angew. Chem. Int. Ed. Engl. 2009, 48, 2398; e) Z. Chen, Y. Aota, H. M. H. Nguyen, V. Dong, Angew. Int. Ed. 2019, 58, 4705.

[12] a) X. Chang, X.-S. Sun, C. Che, Y.-Z. Hu, H.-Y.Tao, C.-J. Wang, Org Lett. 2019, 21, 1191; b) R. Mose, G. Preegel, J. Larsen, S. Jakobsen, E. H. Iversen, K. A. Jørgensen Nat. Chem. 2017, 9, 487; c) M. E. Abbasov, B. M. Hudson, W. Kong, D. J. Tantillo, D, Romo, Org. Biomol. Chem. 2017, 15, 3179; d) S. Crotti, F. Bertolini, V. Di Bussolo, M. Pineschi, Org. Lett. 2010, 12, 1828; e) R. Annunziata, M. Cinquini, F. 
Cozzi, L. Raimondi, G. Licini, Tetrahedron 1991, 47, 3869; f) A. Orue, E. Reyes, J. L. Vicario, L. Carillo, U. Uria, Org. Lett. 2012, 14, 3740.

[13] D. J. Cram, J. R. Knox, J. Am. Chem. Soc. 1961, 83, 2204.

[14] C. O. Kappe, S. S. Murphree, A. Padwa, Tetrahedron 1997, 53, 14179; b) S. Bur, A. Padwa, Methods and applications of cycloaddition reactions in organic synthesis 2014, 355; F. I. Zubkov, E. V. Nikitina, A. V. Varlamov, Russ. Chem. Rev. 2005, 74, 639.

[15] F. W. Lewis, L. M. Harwood, Targets in Heterocyclic Systems 2012, 16 ,

[16] J. D. Brubaker, A. G. Myers, Org. Lett. 2007, 9, 3523.

[17] J. D. Firth, P. G. E. Craven, M. Lilburn. A. Pohl, S. P. Marsden, A. Nelson, Chem. Commun. 2016, 52, 9837.

[18] M. E. Jung, J. Gervay, J. Am. Chem. Soc. 1991, 113, 224

[19] a) C. Andrés, G. Maestro, J. Nieto, R. Pedrosa, S. García-Granda, E. Pérez-Carreño, Tetrahedron Lett. 1997, 38, 1463; b) T. Mukaiyama, N. Iwasawa, Chem. Lett. 1981, 29.
[20] a) H. C. Brown, M. C. Desai, P. K. Jadhav, J. Org. Chem. 1982, 47 $5065 ;$ b) H. C. Brown, J. V. N. Vara Prasad, J. Am. Chem. Soc. 1986 , 108, 2049;

[21] J. Abbott, Org. Syn. 2015, 92, 26.

[22] G. W. Kabalka, T. M. Shoup, N. M. Goudgaon, J. Org. Chem. 1989, 54 5930.

[23] T. R. Hoye, C. S. Jeffrey, F. Shao, Nature Protocols, 2007, 2, 2451.

[24] K. N. Houk, N. G. Rondan, Y. D. Wu, J. T. Metz, M. D. Paddon-Row, Tetrahedron 1984, 40, 2257.

[25] In this medium, hydroboration with $\mathrm{BH}_{3}$ gave a 90:10 mixture of $\mathbf{5 a}$ and 6a upon $\mathrm{NaBO}_{3}$ oxidation, whereas in THF, a 50:50 ratio was obtained. The difference in regiochemical outcomes may be associated with the high proportion of borane monomer (as opposed to unreactive diborane) in THF.

[26] J. C. J. Benningshof, R. H. Blaaw, A. E. van Ginkel, J. H. van Maarseveen, F. P. J. T. Rutjes, H. Hiemstra , J. Chem. Soc. Perkin Trans. 1 2002, 1693. 


\section{COMMUNICATION}

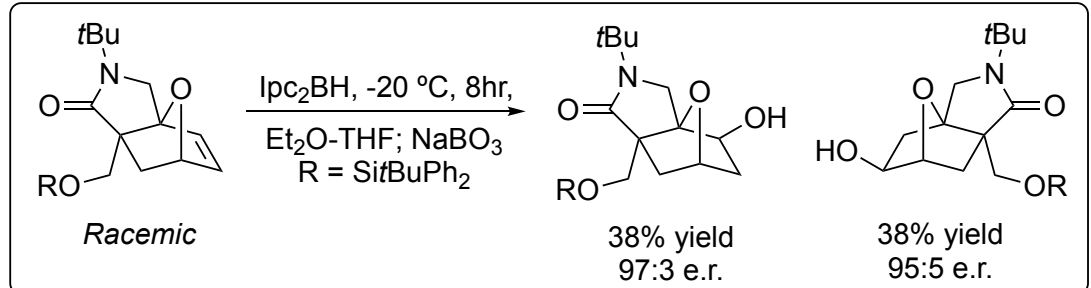

Simple, parallel and dynamic: asymmetric hydroboration reactions of racemic intramolecular Diels-Alder furan (IMDAF) cycloadducts give regiodivergent outcomes in which simple, parallel and dynamic kinetic resolutions of the substrate enantiomers may be observed.

\section{Kinetic Resolution}

Tamara Fulgheri, Philip Cornwall, Andrew R. Turner, Joseph B. Sweeney and Duncan M. Gill*

Page No. - Page No.

Parallel kinetic resolution of intramolecular furan Diels-Alder cycloadducts via asymmetric hydroboration 